

\title{
Commercial Berry Crop Producers' Production and Marketing Strategies in Virginia
}

\author{
Joseph Monson and Denise Mainville ${ }^{1}$
}

ADDITIONAL INDEX WORDs. berries, cluster analysis, extension, educational programming

Summary. Producers in Virginia's agriculture sector are searching for alternatives that offer higher returns per acre than traditional commodity production. One possible alternative is the production of berries such as blueberry (Vaccinium spp.), blackberry (Rubus spp.), raspberry (Rubus spp.), and strawberry (Fragaria spp.) that offer a potentially high-value market and can be produced on smaller-scale farms that are characteristic of the state. A mail survey was used to collect data that were analyzed with cluster analysis with respect to farm characteristics, production techniques, marketing strategies, and producers' socioeconomic characteristics. Three types of producers were identified: producers in Cluster 1 are large-scale producers who market the majority of their products through wholesale and retail outlets such as supermarkets, wholesalers, and auctions; producers in Cluster 2 are small-scale, less experienced growers who mostly sell their output directly to consumers, often through farmers' markets; and producers in Cluster 3 are medium-sized, more experienced producers who are also heavily reliant on direct outlets, particularly pick-your-own operations, to sell their products. These characterizations carry implications for extension programming. For example, producers in Cluster 1 have the potential to increase their sales to market outlets, such as supermarkets, that seek larger volumes of production and that have relatively demanding entry requirements; they thus need programming to identify and respond to these needs. Producers in Cluster 2 are relatively new to production and marketing and would benefit from basic programming relating to farmbusiness planning, production methods, and marketing strategies. Finally, producers in Cluster 3 are distinguished by their diversity and experience in commercial production of berries and would benefit from programming that builds on their considerable experience in and outside of berry production to introduce innovative methods in production and marketing.

Agricultural and Applied Economics, Virginia Polytechnic Institute and State University, Blacksburg, VA 24061

The material presented in this paper is drawn from a master's thesis by J. Monson. Research funding was provided by a grant from the Small Fruit and Specialty Crop Growers' Association of Virginia through a Tobacco Indemnification and Revitalization Grant.

We acknowledge Dr. Daniel Taylor, Dr. Gordon Groover, and Dr. Allen Straw, as well as four anonymous reviewers, for their constructive reviews of this and earlier versions of the manuscript.

${ }^{1}$ Corresponding author. E-mail: mainvill@vt.edu.
$\mathrm{V}$ irginia's agriculture sector faces numerous challenges, including high costs of production, limited potential for scale economies, and development pressures that increase costs and constrain production activities. Consequently, there is a search for alternatives to traditional commodity production that offer higher returns per acre and capitalize on the rapidly expanding suburban and urban populations in the state. This population has growing demand for fresh, high-quality, and wholesome foods, as well as food with intangible attributes such as environmental sustainability, support for local agriculture and economic development, and animal welfare, all of which are often assumed to be inherent in locally produced foods. One possible alternative to commodity production is the production of berries such as blueberry, blackberry, raspberry, and strawberry that offer a potentially high-value market and can be produced on smaller-scale farms that are characteristic of the state. While relatively few producers in Virginia currently grow berry crops commercially, they offer a potentially high-value market and can be produced on smaller-scale farms, making them attractive to producers who are seeking alternatives to commodity production.

A comprehensive mail-based survey was conducted to obtain a better understanding of the current structure and organization of berry crop production in Virginia (Monson, 2007). The objective of this survey was to analyze commercial berry crop operations with respect to farm characteristics, production techniques, marketing strategies, and producer socioeconomic characteristics. Groups of berry producers were characterized using cluster analysis of the survey data. Three types of producers were identified: the first consists of large-scale producers who market the majority of their products through wholesale and retail outlets such as supermarkets, wholesalers, and auctions; the second is comprised of small-scale, less experienced growers who mostly sell their output directly to consumers, often through farmers' markets; and the third is made up of medium-sized, more experienced producers who are also heavily reliant on direct outlets to sell their products, particularly

\begin{tabular}{llll}
\hline $\begin{array}{l}\text { Units } \\
\text { To convert U.S. to SI, } \\
\text { multiply by }\end{array}$ & U.S. unit & SI unit & $\begin{array}{l}\text { To convert SI to U.S., } \\
\text { multiply by }\end{array}$ \\
\hline 0.4047 & acre(s) & ha & 2.4711
\end{tabular}


pick-your-own operations. The characteristics of these clusters and their production and marketing activities are described in this article, with a discussion of the implication of these characterizations for extension programming.

While the results of this research are specific to Virginia, their relevance is broader, as Virginia's situation is similar to that of numerous other states along the eastern seaboard that share relatively small farm sizes, significant urban pressure, and a proximity to large consumer markets.

\section{Materials and methods}

In this study, cluster analysis techniques were used to characterize "types" of berry crop producers. Cluster analysis is a procedure used to classify entities (such as farms) into relatively homogenous groups on the basis of predetermined variables (Aldenderfer and Blashfield, 1984). In this study, the variables used to classify berry crop producers into groups were total farm size, berry crop acreage, the number of different berry crops grown, producers' berry production experience, reliance on direct marketing outlets, and the diversity of sales outlets used. Once clusters were formed, descriptive statistics of farm characteristics and demographics for producers in each group were calculated, and analysis of variance (ANOVA) tests were used to determine whether differences among groups were statistically significant.

Cluster analysis has been widely implemented in numerous disciplines. In the field of agricultural economics, Hardiman et al. (1990) used cluster analysis to classify farming systems in China; Rosenberg and Turvey (1991) employed cluster analysis to categorize management practices implemented by swine producers in Ontario; Poole et al. (1998) used cluster analysis to examine marketing orientations among citrus producers in Spain; and SiegmundSchultze and Rischkowsky (2001) applied clustering techniques to characterize socioeconomic profiles of sheep producers in West Africa.

The two main approaches to clustering are k-means and hierarchical classifications. In hierarchical classifications, the data are not partitioned into a predetermined number of clusters at a single step. This is advantageous in market analysis because the researcher can determine the suitable number of clusters to apportion the objects into based on the objectives of the study (Aldenderfer and Blashfield, 1984). Agglomerative linkage methods are one type of hierarchical clustering method. Agglomerative linkage methods begin by assigning each entity to its own cluster so that there is one "cluster" for each observation. They then progressively reduce the number of clusters through successive fusions between entities or groups of entities that are the most similar with respect to the variables in question until, after a series of successive fusions, all entities are grouped into a single cluster at the end (Everitt, 1993). During each fusion, two objects, two clusters, or an object and a cluster are grouped together according to criteria specified by one of several alternative mathematical algorithms, known as linkage methods. Ward's method is the specific linkage method used to form groupings in this study. Ward's method is widely used as a clustering method in social science research (Aldenderfer and Blashfield, 1984) and works by minimizing the variance within clusters by combining those objects with the lowest increase in the error sum of squares along each stage of the agglomerative schedule (Ward, 1963).

The data come from a 2006 mail survey of commercial berry crop producers in Virginia. We use the term "commercial" in this article to refer to any berry producer who cultivates berries with the intent of selling them, and do not imply any level of scale or professionalism in our use of the term. Because a comprehensive list of berry crop growers in Virginia was not available, potential respondents were identified through public agency listings and producer lists available through private producer associations. In all, $\approx 1250$ surveys were sent to possible berry crop or specialty crop growers in Virginia, with 345 usable surveys completed and returned. Of the 345 usable responses, 115 were from producers currently involved in commercial berry crop production. Due to missing values in one or more of the variables used to form clusters, 18 cases were deleted from the original sample. Thus, the analysis uses a total sample of 97 commercial berry crop growers. This sample accounts for $31 \%$ of the total number of producers identified in the Census of Agriculture [U.S. Department of Agriculture (USDA), 2004] as growing berry crops commercially in the state. According to Salant and Dillman (1994), one can be $95 \%$ confident tfhat this particular sample size will generate estimates that are within $\pm 5 \%$ of the true population parameter. Thus, it can be argued that the results reported below are representative of berry crop growers in Virginia.

\section{Results and discussion}

The responses from the survey were grouped into three distinct clusters. Cluster 1 consists of large-scale producers who market the majority of their products through indirect outlets such as retailers and wholesalers; Cluster 2 is comprised of small-scale, less experienced growers who mostly sell their output directly to consumers; and Cluster 3 is made up of medium-sized, more experienced producers who are also heavily reliant on direct outlets to sell their products. One-way ANOVA confirms that the means of each of the six variables used to form the clusters are statistically different among the groups (Table 1). Tables 2 through 8 present the results of the characterization of producers in each cluster as well as tests for differences in means among groups with respect to farm characteristics, production activities and methods, marketing methods, labor use, and sociodemographic characteristics. The following three subsections provide a detailed description of berry producers in each cluster. Discussion of differences between different clusters is limited to results that are statistically significant at a $90 \%$ or higher confidence level.

Cluster 1: Indirect outletDEPENDENT, LARGER-SCALE PRODUCERS. Producers in Cluster 1 represent 39\% of the sample. All of the large farming operations in the sample are represented in this cluster (the cluster mean is 132 acres), but it should be noted that there is also a number of producers with relatively smaller total acreage in the cluster as indicated by median total farm acreage of 20 acres. Producers in this cluster rely heavily on indirect outlets to sell their 
Table 1. Summary of farm and berry production characteristics used to categorize farmers, with results of tests for statistical significance of differences in mean values among clusters.

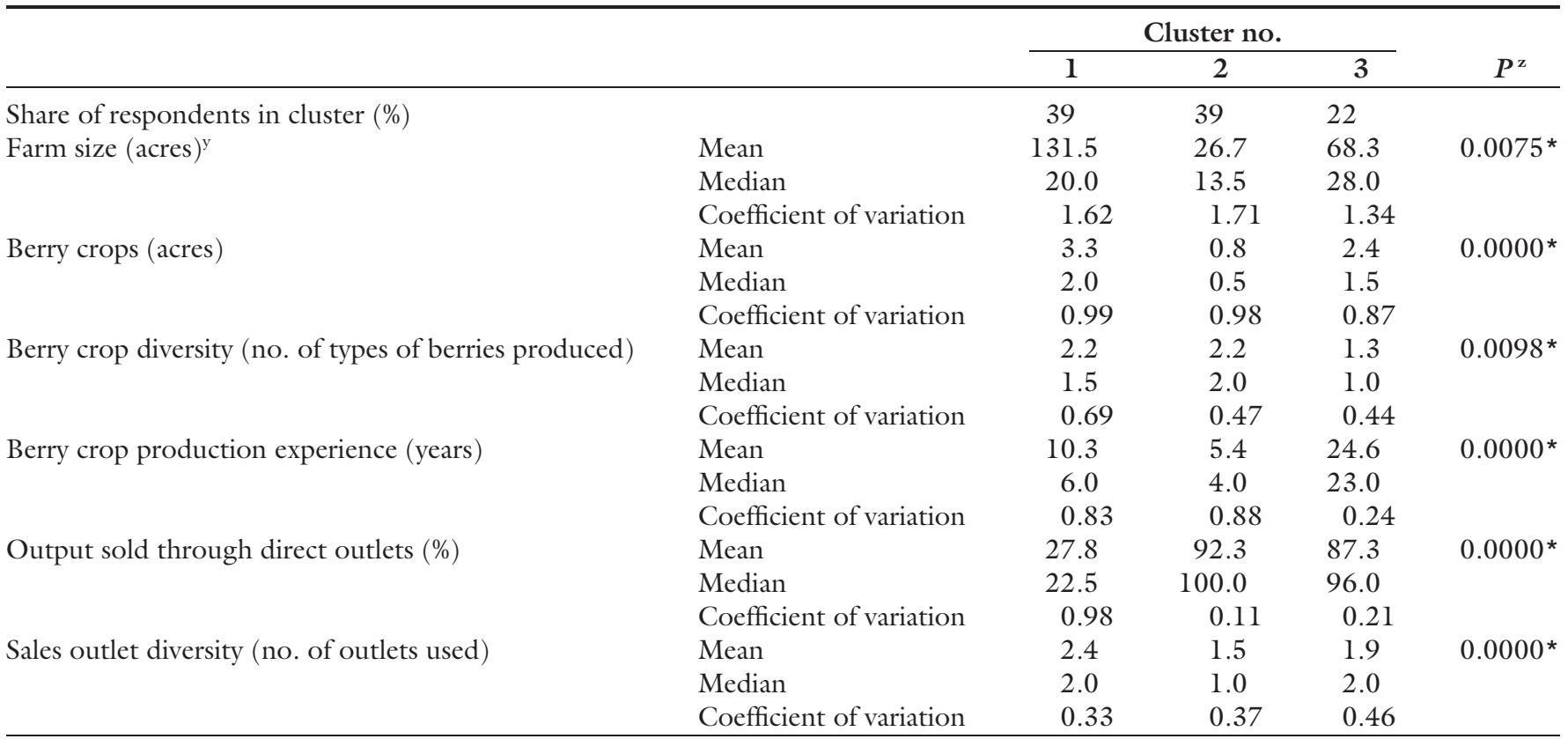

${ }^{\mathrm{z}}$ An asterisk denotes statistical significance of at least the 0.10 level.

${ }^{\mathrm{y}} \mathrm{l}$ acre $=0.4047 \mathrm{ha}$.

Table 2. Characteristics of survey respondents' indirect marketing strategies, with results of tests for statistical significance of differences in mean values among clusters.

\begin{tabular}{|c|c|c|c|c|}
\hline \multirow[b]{2}{*}{ Mean values for respondents in cluster } & \multicolumn{3}{|c|}{ Cluster no. } & \multirow[b]{2}{*}{$P^{\mathrm{z}}$} \\
\hline & 1 & 2 & 3 & \\
\hline Sales outlet diversity (no. of outlets used) & 2.4 & 1.5 & 1.9 & $0.000^{*}$ \\
\hline \multicolumn{5}{|l|}{ Share of growers who sell to: } \\
\hline Retail and wholesale outlets (\%) & 66 & 34 & 38 & $0.013^{*}$ \\
\hline Processor and food service outlets (\%) & 47 & 8 & 33 & $0.000 *$ \\
\hline Share of output sold through indirect outlets (\%) & 72 & 8 & 13 & $0.000 *$ \\
\hline \multicolumn{5}{|l|}{ Share of sales per outlet by producers using outlet: ${ }^{y}$} \\
\hline Retail and wholesale outlets (\%) & 52 & 69 & 41 & 0.222 \\
\hline Processor and food service outlets (\%) & 24 & 15 & 42 & 0.134 \\
\hline Auctions and shipping point markets (\%) & 17 & 11 & 8 & 0.694 \\
\hline
\end{tabular}

${ }^{\mathrm{z}}$ An asterisk denotes statistical significance of at least the 0.10 level.

y These numbers need not add to 100 because not all farmers are represented among all categories of market outlet.

products (accounting for $72 \%$ of their sales on average) and the average producer sells to 2.4 different outlets (Table 1). Ninety-seven percent of producers in this cluster sell to at least one indirect outlet, compared with only $57 \%$ and $47 \%$ of producers in Clusters 3 and 2, respectively (Table 2 ). Such indirect outlets include retail and wholesale buyers (used by $66 \%$ of the producers in the cluster and accounting for $52 \%$ of their sales), processors and food service businesses (used by $47 \%$ of the producers and accounting for $24 \%$ of their sales), and auction and shipping point farmers' markets (used by $32 \%$ of the producers in the cluster and accounting for $17 \%$ of their sales) (Table 2).

In addition to berry crops, producers in this cluster dedicate a significant amount of their farmland to other agricultural activities. Fruit, vegetables, and the production of other specialty products are of particular importance, as $50 \%$ dedicate $22 \%$ of their land to the production of nonberry fruit on average, $79 \%$ dedicate an average of $19 \%$ of their land to vegetables, and $47 \%$ produce some other sort of specialty product (Table 3 ). More than one-third of the producers in this group $(38 \%)$ report that they produce with organic methods, though few of them are either certified or in transition to organic certification, which limits their marketing opportunities (Table 4 ). There are no statistically significant differences in the use 
Table 3. Characteristics of survey respondents' farm characteristics, with results of tests for statistical significance of differences in mean values among clusters.

\begin{tabular}{|c|c|c|c|c|}
\hline \multirow[b]{2}{*}{ Mean values for respondents in cluster } & \multicolumn{3}{|c|}{ Cluster no. } & \multirow[b]{2}{*}{$P^{\mathrm{z}}$} \\
\hline & 1 & 2 & 3 & \\
\hline Farm size $(\text { acres })^{\mathrm{y}}$ & 131.5 & 26.7 & 68.3 & $0.0075^{*}$ \\
\hline Fruit, other than berry crops $(\%)$ & 50 & 47 & 43 & 0.8743 \\
\hline Vegetables $(\%)$ & 79 & 68 & 81 & 0.4582 \\
\hline Row crops $(\%)$ & 21 & 16 & 24 & 0.7335 \\
\hline \multicolumn{5}{|l|}{ Production area: ${ }^{\mathrm{x}}$} \\
\hline Berry crops (acres) & 3.3 & 0.8 & 2.4 & 0.0000 * \\
\hline Fruit, other than berry crops (acres) & 19.3 & 3.0 & 1.3 & 0.1649 \\
\hline Vegetables (acres) & 16.3 & 3.1 & 17.7 & 0.1516 \\
\hline Row crops (acres) & 11.4 & 0.3 & 26.7 & 0.1229 \\
\hline Fruit, other than berry crops $(\%)$ & 22 & 22 & 3 & 0.0320 * \\
\hline Vegetables (\%) & 19 & 22 & 36 & 0.3090 \\
\hline Row crops $(\%)$ & 13 & 2 & 54 & 0.0360 * \\
\hline Pasture or hay, livestock, or dairy (\%) & 43 & 46 & 3 & 0.2520 \\
\hline Other specialty crops $(\%)$ & 0 & 1 & 0 & 0.1690 \\
\hline
\end{tabular}

${ }^{\mathrm{z}}$ An asterisk denotes statistical significance of at least the 0.10 level.

${ }^{y} 1$ acre $=0.4047$ ha.

xProduction acreage does not necessarily sum to total farm size as total farm size includes land not in production.

wThese numbers need not add to 100 because not all farmers are represented among all categories of market outlet.

Table 4. Characteristics of survey respondents' production methods and technology use, with results of tests for statistical significance of differences in mean values among clusters.

\begin{tabular}{|c|c|c|c|c|}
\hline \multirow[b]{2}{*}{ Mean values for respondents in cluster } & \multicolumn{3}{|c|}{ Cluster no. } & \multirow[b]{2}{*}{$P^{\mathrm{z}}$} \\
\hline & 1 & 2 & 3 & \\
\hline \multicolumn{5}{|l|}{ Organic production: } \\
\hline Organic production; not certified (\%) & 32 & 34 & 57 & 0.1416 \\
\hline Organic production; certified or in transition (\%) & 6 & 11 & 14 & 0.5197 \\
\hline Organic area $(\text { acres })^{\mathrm{y}}$ & 7.4 & 3.6 & 15.0 & $0.0577^{*}$ \\
\hline Use high tunnels (\%) & 5 & 12 & 8 & 0.7393 \\
\hline Use greenhouses (\%) & 5 & 12 & 15 & 0.5825 \\
\hline Use irrigation (\%) & 87 & 72 & 78 & 0.3766 \\
\hline Use plasticulture (\%) & 44 & 24 & 44 & 0.3116 \\
\hline
\end{tabular}

${ }^{\mathrm{z}}$ An asterisk denotes statistical significance of at least the 0.10 level.

yl acre $=0.4047$ ha.

of irrigation and crop protection materials among producers in the different clusters.

The average producer in this cluster grows 3.3 acres of berry crops, which significantly exceeds the 0.8 acres grown by the average producer in Cluster 2 and the 2.4 acres grown by the average producer in Cluster 3 (Table 3 ). Within this acreage, the average producer in Cluster 1 grows a diverse mix of berries (Table 5). Blackberry, strawberry, and blueberry are particularly important to this cluster, as $58 \%, 53 \%$, and $45 \%$ of the growers in the cluster cultivate an average of nearly 1 acre each, respectively.

Producers in this cluster tend to rely on hired labor to run their operations (Table 6). Namely, the average producer in this group hires nine laborers during his or her busiest time of the year, while the average producers in Clusters 2 and 3 hire a maximum of three laborers and eight laborers, respectively, at comparable times.
Demographically, the typical principal operator in this cluster is from 45 to 59 years old, white, and male (Table 7). About half of the average producer's annual household income comes from farming and $28 \%$ of his or her farming income comes from berry crop sales specifically. Geographically, producers in the cluster are spread out across the state, although they have a heavy representation in counties that are facing particularly heavy development pressures. 
Table 5. Characteristics of survey respondents' berry crop production activities, with results of tests for statistical significance of differences in mean values among clusters.

\begin{tabular}{|c|c|c|c|c|}
\hline \multirow[b]{2}{*}{ Mean values for respondents in cluster } & \multicolumn{3}{|c|}{ Cluster no. } & \multirow[b]{2}{*}{$P^{\mathrm{z}}$} \\
\hline & 1 & 2 & 3 & \\
\hline Types of berries grown (no.) & 2.2 & 2.2 & 1.3 & 0.0098 * \\
\hline Strawberry (\%) & 53 & 42 & 57 & 0.4876 \\
\hline Blueberry (\%) & 45 & 53 & 52 & 0.7604 \\
\hline Blackberry (\%) & 58 & 42 & 14 & $0.0045^{*}$ \\
\hline Other berries $(\%)$ & 11 & 11 & 0 & 0.3066 \\
\hline \multicolumn{5}{|l|}{ Berry crop acreage: } \\
\hline Strawberry $(\text { acres })^{\mathrm{y}}$ & 0.7 & 0.2 & 1.3 & $0.0116^{*}$ \\
\hline Blueberry (acres) & 0.7 & 0.4 & 0.7 & 0.5408 \\
\hline Blackberry (acres) & 1.0 & 0.2 & 0.1 & 0.0325 * \\
\hline Strawberry $(\%)$ & 24 & 20 & 62 & 0.0840 * \\
\hline Blueberry (\%) & 24 & 40 & 33 & 0.1870 \\
\hline Blackberry (\%) & 34 & 20 & 5 & 0.0940 * \\
\hline Summer-bearing raspberry $(\%)$ & 7 & 10 & 0 & 0.0070 * \\
\hline Fall-bearing raspberry (\%) & 3 & 10 & 0 & 0.1630 \\
\hline Other berries $(\%)$ & 7 & 0 & 0 & 0.2790 \\
\hline
\end{tabular}

${ }^{\mathrm{z}}$ An asterisk denotes statistical significance of at least the 0.10 level.

y l acre $=0.4047$ ha

Table 6. Characteristics of survey respondents' labor use and constraints to expansion, with results of tests for statistical significance of differences in mean values among clusters.

\begin{tabular}{|c|c|c|c|c|}
\hline \multirow[b]{2}{*}{ Mean values for respondents in cluster } & \multicolumn{3}{|c|}{ Cluster } & \multirow[b]{2}{*}{$P^{\mathrm{z}}$} \\
\hline & 1 & 2 & 3 & \\
\hline Peak number of laborers used during season (no.) & 9.0 & 2.8 & 8.2 & $0.0355^{*}$ \\
\hline Seasonal labor (no. of workers hired annually) & 6.7 & 2.1 & 7.1 & 0.0460 * \\
\hline \multicolumn{5}{|l|}{ Share of total labor hired: } \\
\hline Permanent $(\%)$ & 23 & 10 & 14 & 0.3390 \\
\hline Limited by cost of labor (\%) & 55 & 43 & 30 & 0.1801 \\
\hline Unable to find qualified workers (\%) & 29 & 22 & 35 & 0.5442 \\
\hline Unable to find enough workers (\%) & 18 & 11 & 25 & 0.3797 \\
\hline Limited by other labor constraints (\%) & 21 & 14 & 15 & 0.6704 \\
\hline
\end{tabular}

${ }^{\mathrm{z}}$ An asterisk denotes statistical significance of at least the 0.10 level.

Interestingly, these producers, who do the least amount of direct marketing of any of the clusters, are in opportune positions to expand their direct sales to consumers due to their proximity to rapidly expanding population centers.

Cluster 2: Direct outletDEPEN DENT, SMALLER - SCALE PRODUCERS. Producers in this cluster represent $39 \%$ of the sample (Table 1). This cluster is largely made up of "hobby farmers" who operate small farms, have less production experience, and are not heavily reliant on farm sales for their household incomes. Specifically, the mean farm size in this cluster is only 27 acres and the median only 14 acres, of which an average of 0.8 acre is devoted to berry crop production. Most producers in this cluster have farmed their land 5 years or less, with the average producer in this group having only 5 years of experience growing berry crops, compared with the average producer in Clusters 1 and 3 who have 10 and 25 years of experience growing berry crops, respectively.

The average producer in this group is considerably more reliant on direct markets to sell his or her products than those in Clusters 1 and 3 , marketing $92 \%$ of his or her total output through direct outlets (Table 1). Farmers' markets are the most frequently used direct outlet by producers in this cluster, as $71 \%$ of the producers in this cluster use farmers' markets to sell all or a portion $(53 \%$ on average) of their products directly to consumers (Table 8). Farm stands and pick-your-own operations are second and third in importance for producers in this group who direct market to consumers. 
Table 7. Survey respondents' demographic and socio-economic characteristics, with results of tests for statistical significance of differences in mean values among clusters.

\begin{tabular}{|c|c|c|c|c|}
\hline \multirow[b]{2}{*}{ Mean values for respondents in cluster } & \multicolumn{3}{|c|}{ Cluster } & \multirow[b]{2}{*}{$P^{\mathrm{z}}$} \\
\hline & 1 & 2 & 3 & \\
\hline Ethnicity: White, non-Hispanic (\%) & 100 & 97 & 76 & $0.0007^{*}$ \\
\hline \multicolumn{5}{|l|}{ Age distribution of respondents: } \\
\hline Under 25 years old (\%) & 3 & 0 & 0 & 0.4771 \\
\hline Between 25 and 44 years old (\%) & 18 & 38 & 10 & $0.0357^{*}$ \\
\hline Between 45 and 59 years old (\%) & 42 & 41 & 25 & 0.4129 \\
\hline Between 60 and 69 years old (\%) & 26 & 19 & 50 & $0.0425^{*}$ \\
\hline Over 69 years old (\%) & 11 & 3 & 15 & 0.2391 \\
\hline Gender: female (\%) & 32 & 30 & 40 & 0.7372 \\
\hline \multicolumn{5}{|l|}{ Education of respondents: } \\
\hline No high school diploma (\%) & 3 & 0 & 5 & 0.4705 \\
\hline High school diploma (\%) & 11 & 11 & 14 & 0.9080 \\
\hline Some college (\%) & 16 & 14 & 14 & 0.9725 \\
\hline Associates degree (\%) & 11 & 3 & 10 & 0.4128 \\
\hline Bachelors degree (\%) & 32 & 47 & 33 & 0.3471 \\
\hline Graduate degree (\%) & 29 & 25 & 24 & 0.8919 \\
\hline Household size (no. of people) & 3.4 & 3.1 & 2.5 & 0.1754 \\
\hline \multicolumn{5}{|l|}{ Household income of respondents: } \\
\hline Less than $\$ 20,000(\%)$ & 0 & 0 & 0 & $\mathrm{~N} / \mathrm{A}$ \\
\hline Between $\$ 20,000$ and $\$ 39,999(\%)$ & 23 & 18 & 5 & 0.2624 \\
\hline Between $\$ 40,000$ and $\$ 59,999(\%)$ & 33 & 42 & 42 & 0.7322 \\
\hline Between $\$ 60,000$ and $\$ 79,999(\%)$ & 20 & 12 & 0 & 0.1164 \\
\hline Between $\$ 80,000$ and $\$ 99,999(\%)$ & 7 & 12 & 16 & 0.5967 \\
\hline$\$ 100,000$ or more $(\%)$ & 17 & 15 & 37 & 0.1439 \\
\hline Household income from farming (\%) & 50 & 37 & 51 & 0.2858 \\
\hline Farming income from berry crop sales (\%) & 28 & 20 & 29 & 0.5944 \\
\hline Farming income from direct sales (\%) & 38 & 76 & 81 & $0.0000^{*}$ \\
\hline Own all land in production (\%) & 89 & 89 & 95 & 0.7071 \\
\hline \multicolumn{5}{|l|}{ Experience of respondents: } \\
\hline Farmed land $0-5$ years $(\%)$ & 16 & 35 & 10 & $0.0383^{*}$ \\
\hline Farmed land $6-20$ years $(\%)$ & 39 & 32 & 24 & 0.4772 \\
\hline Farmed land 21 or more years (\%) & 26 & 16 & 52 & $0.0116^{*}$ \\
\hline Farmed land for multiple generations (\%) & 18 & 16 & 14 & 0.9185 \\
\hline Berry crop production experience (years) & 10.3 & 5.4 & 24.6 & $0.0000^{*}$ \\
\hline
\end{tabular}

${ }^{2}$ An asterisk denotes statistical significance of at least the 0.10 level.

Producers in this cluster are similar to those in Cluster 1 in terms of their tendency to produce other fruit, vegetables, and other specialty products in combination with berries. Forty-seven percent produce fruit other than berries on an average of $22 \%$ of their land, $68 \%$ produce vegetables on an average of $22 \%$ of their land, and $45 \%$ produce some other specialty product (Table 3 ).

Growers in this cluster produce 2.2 different types of berries on average, with a broad distribution among the different berry types. That said, summer and fall-bearing raspberries are produced by a higher percentage of producers in this cluster than in the other clusters (Table 5). Similar to the producers in Cluster 1 , relatively few producers (only 45\%) implement organic production processes on their farming operation, and little of that reported acreage is either certified or in transition to organic certification (Table 4). Furthermore, producers in this cluster who do report organic production have the smallest total acreage devoted to organic production, on average at only 3.6 acres compared with 7 acres for those in Cluster 1 and 15 acres for those in Cluster 3 .

Labor is not hired very frequently by producers in this cluster (Table 6). In fact, the average producer employs only two seasonal laborers and no permanent workers in the course of a year, significantly less than the other clusters' producers.

The lack of farming experience of the producers in this cluster may be partially explained by a predominance of younger individuals in this group compared with others (Table 7). Specifically, $38 \%$ of the producers in this group are between 25 and 44 years old, compared with producers in both other clusters who are concentrated in the 45 to 59 years and 60 to 69 years age ranges.

Cluster 3: Direct outletDE PEN DEN T, ME D I U M - S C A LE PRODUCERS. Producers in this group represent the remaining $22 \%$ of the sample. This cluster consists of a diverse group of experienced farmers who rely heavily on sales direct to consumers to market their products. Compared with Clusters 1 and 2, the average producer in this cluster operates a medium size farm (68 acres at the mean) and produces an intermediate level of berry crops (2.4 acres) (Table 1). On average, producers in this cluster have 25 years of experience growing berry crops, which is about twice as many years of experience as the average producer in Cluster 1 and five times that of the average producer in Cluster 2 (Table 1). 
Table 8. Characteristics of survey respondents' direct marketing strategies, with results of tests for statistical significance of differences in mean values among clusters.

\begin{tabular}{|c|c|c|c|c|}
\hline \multirow[b]{2}{*}{ Mean values for respondents in each cluster } & \multicolumn{3}{|c|}{ Cluster } & \multirow[b]{2}{*}{$P^{\mathrm{z}}$} \\
\hline & 1 & 2 & 3 & \\
\hline Number of different direct outlets used (no.) & 1.8 & 1.5 & 2.3 & 0.0258 * \\
\hline \multicolumn{5}{|l|}{ Growers who sell through: } \\
\hline U-pick operations (\%) & 63 & 26 & 70 & $0.0013^{*}$ \\
\hline Farmers' markets (\%) & 63 & 71 & 53 & 0.4326 \\
\hline CSA programs $(\%)^{\mathrm{y}}$ & 10 & 9 & 16 & 0.7218 \\
\hline Other direct outlets (\%) & 30 & 15 & 26 & 0.3289 \\
\hline Output sold through direct outlets (\%) & 28 & 92 & 87 & $0.0000^{*}$ \\
\hline \multicolumn{5}{|l|}{ Direct sale output sold through: } \\
\hline U-pick operations (\%) & 28 & 16 & 39 & $0.0887^{*}$ \\
\hline Farmers' markets $(\%)$ & 43 & 53 & 35 & 0.3578 \\
\hline Other direct outlets (\%) & 9 & 4 & 2 & 0.3899 \\
\hline Peak number of daily customers during season (no.) & 117 & 126 & 870 & 0.0372 * \\
\hline Number of different advertising methods used (no.) & 2.8 & 2.8 & 3.9 & 0.1039 \\
\hline \multicolumn{5}{|l|}{ Advertising methods used by respondents: } \\
\hline Word of mouth $(\%)$ & 84 & 89 & 93 & 0.7113 \\
\hline Newspapers (\%) & 44 & 41 & 64 & 0.3365 \\
\hline Road signs (\%) & 41 & 33 & 71 & 0.0589 * \\
\hline Personal websites (\%) & 22 & 33 & 21 & 0.5629 \\
\hline Paid internet sites (\%) & 6 & 0 & 0 & 0.2762 \\
\hline Direct mailings (\%) & 19 & 22 & 43 & 0.2100 \\
\hline Telephone directories (\%) & 13 & 11 & 29 & 0.2968 \\
\hline
\end{tabular}

${ }^{2}$ An asterisk denotes statistical significance of at least the 0.10 level.

${ }^{y}$ Community-supported agriculture.

The average producer in this cluster grows a less diverse mix of berries than producers in Clusters 1 and 2 (Table 5 ). Strawberry and blueberry dominate the berry production activities of producers in this cluster. Specifically, $57 \%$ of the producers in this group grow strawberries on an average of $62 \%$ of their total berry crop acreage, and $52 \%$ grow blueberries on an average of $33 \%$ of their total land devoted to berry crop production.

In addition to berry crops, $81 \%$ of the growers in this cluster produce vegetables, with these producers devoting $36 \%$ of their farm land to vegetable production (Table 3 ). Unlike producers in Clusters 1 and 2, organic production methods are very popular, with $71 \%$ of the producers reporting their use and those who do use them producing with organic methods on an average of 15 acres (Table 4). Nevertheless, only onequarter of those producing with organic methods are either USDA certified or in transition to certification.
The average producer in this cluster sells $87 \%$ of his or her total output through direct outlets (Table 1 ), and earns $81 \%$ of his or her total farming income from sales direct to consumers (Table 7). Producers in this cluster market their products though a diverse set of direct outlets, dominated by pick-your-own operations (used by $70 \%$ of the producers in the cluster to market $39 \%$ of their product), farm stands (used by $63 \%$ of the producers in the cluster to market $20 \%$ of their product), and farmers' markets (used by $53 \%$ of the producers in the cluster to market $35 \%$ of their product) (Table 8 ).

Demographically, this cluster is more diverse than Clusters 1 and 2 (Table 7). Twenty-four percent are of nonwhite ethnic backgrounds, compared with only $3 \%$ in Cluster 2 and no producers in Cluster 1. Likewise, $40 \%$ of the growers in this group are female; the highest representation in any cluster. The wealth of experience of this cluster may be explained by its age distribution, which is comprised of the highest proportion of producers in the two oldest age categories. For example, $50 \%$ of the producers in this group are from 60 to 69 years old, compared with only $26 \%$ in Cluster 1 and 19\% in Cluster 2 (Table 7).

\section{Conclusion}

The cluster analysis of berry crop producers provides considerable insight into the characteristics of commercial berry crop production and marketing in Virginia. In summary, Cluster 1 consists of mostly largerscale producers who grow a diverse mix of berry crops, including blackberry, strawberry, and blueberry, and sell them in indirect market outlets; Cluster 2 is made of smaller-scale farmers who are also diverse in their berry crop mix and rely heavily on farmers' markets to sell their output; and Cluster 3 is comprised of 
medium-scale growers who produce mostly strawberries and blueberries and market these direct to consumers, often through pick-your-own operations.

When taken together, these results offer insight that can be used to strengthen extension programming and other educational activities for berry producers. Cluster 1 producers are fairly experienced but face challenges of marketing to generally more demanding markets, thus they likely face challenges such as food safety and "good agricultural practice" (GAP) certification, traceability, and other requirements that are typically characteristic of these markets. Also, the prevalence of many of these producers near rapidly expanding residential populations points to the possibility for investments in new market outlets; in particular, direct sales to consumers and restaurants. Production and marketing educational programs must be tailored to meet the specific needs of producers seeking to maintain or expand their market share. These markets' requirements continually evolve such that educators or consultants must maintain direct contact with growers. Examples of specific educational programs that would likely be wellplaced include one-on-one sales training, merchandising and selling at farmers' markets, and selling direct to local chefs. Extension educators would do well to establish representative advisory groups to identify critical needs and training to support cost-effective adoption of new technologies as they are made available.

Cluster 2 is comprised largely of small-scale hobby farmers who are relatively new to production and reliant on direct sales to consumers. Educational needs for these producers will typically be more focused on basic programming relating to farm-business planning, production methods, and marketing strategies. Educational programs on these issues would serve the producers in this cluster well if they were run in workshop formats and actually included activities aimed at addressing issues in the context of producers' own farms and developing draft plans rather than expecting the producers to be able to absorb relatively more abstract information and put it into play independently. Other specific programming that would benefit these producers could focus on helping producers to diversify their market outlets, for example, including expanding their sales to local chefs and foodservice distributors.

Cluster 3 is relatively diverse socioeconomically and is also distinguished by its significant degree of experience in commercial production of berry crops. These producers are also heavily reliant on direct markets, but those who use indirect outlets sell a large portion of their product through them. These producers also produce a disproportionate amount of strawberries and a low diversity of berry crops in general relative to the other clusters. Given that strawberries are a relatively low margin product and offer higher production risk, and given the overall make-up of these producers' activities, educational programming to them would do well to focus on expansion of markets and diversification of products to take advantage of potentially more lucrative market opportunities and manage risk. These producers are arguably in a good position to take advantage of such opportunities given their accrued experience in berry production and marketing in terms of years of experience, sales to direct and indirect outlets, and production methods. These producers have a wealth of resources available in terms of their financial and educational capacities. They also likely bring in a diversity of experience from unrelated fields and are in a position to develop and pursue innovative approaches to production and marketing. Nevertheless, it is possible that some such producers might delve into the innovations without establishing a basic foundation for the enterprise, and hence they would benefit from educational programs like those for the producers in Cluster 2 though the appropriate pace and coverage of these programs might differ. The needs of this group are also likely to be quite diverse such that it is appropriate that individuals be surveyed about their needs before being recruited for specific programs, and that a diversity of programs be designed for the producers' backgrounds, for example, tailoring programs separately for those producers who have prior agricultural experience versus prior business experience, etc.

\section{Literature cited}

Aldenderfer, M.S. and R.K. Blashfield. 1984. Cluster analysis. Sage, Beverly Hills, CA.

Everitt, B.S. 1993. Cluster analysis. Halsted, New York.

Hardiman, R.T., R. Lacey, and Y.M. Yi. 1990. Use of cluster analysis for identification and classification of farming systems in Qingyang County, central North China. Agr. Syst. 30:115-125.

Monson, J. 2007. A market analysis for small fruits in Virginia. Virginia Polytechnic Institute and State University, Blacksburg, Master's thesis. I Aug. 2009. <http:// scholar.lib.vt.edu/theses/available/etd05132008-114411/unrestricted/2008_ 05_13_Monson_Thesis_Final_Version. pdf>.

Poole, N.D., F.J. Del Campo Gomis, J.F. Julia Igual, and F.V. Gimenez. 1998. Formal contracts in fresh produce markets. Food Policy 23:131-142.

Rosenberg, A. and C.G. Turvey. 1991. Identifying management profiles of Ontario swine producers through cluster analysis. Rev. Agr. Econ. 13:201-213.

Salant, P. and D.A. Dillman. 1994. How to conduct your own survey. Wiley, New York.

Siegmund-Schultze, M. and B. Rischkowsky. 2001. Relating household characteristics to urban sheep keeping in West Africa. Agr. Syst. 67:139-152.

U.S. Department of Agriculture (USDA). 2004. Virginia state and county data. 2002 Census of agriculture, Issued June. l May 2007. <http://www.nass.usda. gov/census/census02/volumel/va/ VAVolume104.pdf>

Ward, J.H., Jr. 1963. Hierarchical grouping to optimize an objective function. J. Amer. Stat. Assn. 58:236-244. 